\title{
Relações de Trabalho e Inovação Tecnológica na Gerência de Sistemas de uma Organização Produtora de Jornais
}

\author{
José Armando Ansaloni \\ Angelo Brigato Ésther
}

\section{ResUMO}

Estudou-se a gerência de sistemas de produção de jornais de uma empresa de comunicações, objetivando identificar e analisar os impactos da adoção de novas tecnologias de produção e da definição de novas áreas de atuação sobre as relações de trabalho. Entrevistaram-se empregados do setor de produção e pré-impressão de jornais, coletando-se informações quanto à situação de trabalho no momento atual e no período imediatamente anterior à implantação da nova tecnologia. Observou-se que cargos e funções foram eliminados e que o processo de trabalho foi amplamente remodelado, alcançando-se a instância da gestão da força de trabalho, em que se estabeleceram relações mais flexíveis e liberais. Houve aperfeiçoamento de processos, com alguns traços de reengenharia de processo. Departamentos se tornaram equipes de trabalho, com supervisão flexibilizada, no esforço de se promover interação e participação do empregado. A atitude mais democrática assumida pelas chefias também parece ter contribuído para a evolução das relações de trabalho e para o aumento da produtividade na organização; no entanto algumas práticas da organização remontam a um modelo tradicional de gestão e de relações de trabalho. A adoção de novas tecnologias de produção é encarada como fator positivo, necessário e inadiável.

Palavras-chaves: mudança organizacional; relações de trabalho; inovação; reestruturação produtiva.

\begin{abstract}
Management of production systems of newspapers in a communication corporation were studied, aiming to identify and analyse the impact of adopting new technologies of production and definition of new acting areas in labour relations. Employees in producting and pre-printing of newspapers were interviewed to give us informations concerning the present work situation and that of the period immediately prior to the adoption of the new technology. Employment and jobs were observed to be eliminated and the labour process was widely remodelled, the management of the labour force achieving more flexible and liberal forms. There was a process improving with some traits of reengineering process. Departaments became work teams, with smoothed supervison, in an endeavour to promote employee's integration and paticipation in the process. The more democratic attitude assumed by the leaders also seems to have contributed to the evolution in labour relations and in the increase of productivity. However some practices of the organization constitute rather a traditional management and labour relations model. The adoption of new technologies of production is faced as a positive and necessary factor which cannot be put off.
\end{abstract}

Key words: organizational change; labour relations; innovation; productive reorganization. 


\section{INTRODUÇÃO}

A inovação tecnológica, sobretudo aquela baseada na microeletrônica, vem-se difundindo em ritmo considerado alucinante por muitos. Embora se trate de afirmação incontestável, certamente tanto a velocidade quanto a intensidade dos impactos da inovação variam de acordo com as demandas e exigências de cada segmento do mercado. De todo o modo, tais aspectos vêm preocupando os cientistas sociais, quanto às transformações que estão ocorrendo no processo produtivo e na própria organização do trabalho, essencialmente no que diz respeito aos seus impactos sobre as condições de trabalho, nível de emprego, renda e qualificação (Leite, 1994).

Num ambiente cada vez mais globalizado, a tecnologia é um imperativo, pois é capaz de gerar alta produtividade num mercado regido pela concorrência acirrada. Ao mesmo tempo, é a tecnologia, principalmente aquela referente às telecomunicações, aos transportes e à informática em geral, que propicia a configuração desse ambiente.

Assim, as chamadas relações de trabalho, que aqui terão significado mais amplo, estão na ordem do dia, por ser nessa instância que o avanço tecnológico mais se faz sentir: a tecnologia de operação costuma acompanhar as mudanças na tecnologia de gestão do trabalho.

Tal é a temática desenvolvida, tendo como cenário privilegiado de análise uma empresa de jornais de grande circulação no Estado de Minas Gerais. Longe da pretensão de esgotar o assunto, pretendeu-se, a partir da ótica dos entrevistados, observar aspectos concernentes às mudanças organizacionais introduzidas e seus impactos sobre as relações de trabalho.

\section{A Mudança Organizacional}

A busca de novos modos de aperfeiçoamento de gestão e de melhoria do desempenho tem ensejado o surgimento de inúmeras experimentações e abordagens teóricas, que diferem significativamente em abrangência e em profundidade. De modo semelhante, as técnicas de intervenção têm trafegado entre o conservadorismo e a radicalidade (Gonçalves, 1994), traduzindo-se em expressões como desenvolvimento de processos, melhoria contínua, redesenho de processos e reengenharia, 
entre outras, que abarcam técnicas e conjuntos de técnicas utilizados na reformulação de empresas.

As intervenções se podem dar tanto na melhoria de procedimentos existentes quanto na mudança mais radical da maneira de operar. Enquanto as técnicas típicas de qualidade privilegiam uma visão de atividades, a reengenharia aborda a organização sob o ponto de vista de processos empresariais e, entre esses extremos, enquadram-se várias outras técnicas, de acordo com a profundidade, abrangência e grau de radicalidade do processo de mudança.

Como as organizações apresentam estruturas e necessidades diferentes, requerem técnicas diversificadas de mudança ${ }^{(1)}$. Semelhantemente, é possível observarse numa única organização a necessidade de adoção de técnicas diferentes segundo os processos a ser implementados, ajuste ou mudança radical. Como característica básica das novas maneiras de operar, observa-se uma tendência à mudança substancial no funcionamento da organização, que irá processar-se em vários níveis (Hammer e Champ, 1994):

. de departamentos as unidades de trabalho passam a equipes de processo;

. o serviço se torna multidimensional;

. anteriormente definidos e controlados, os papéis passam a ser desenhados pelas próprias pessoas;

. de supervisores os gerentes evoluem para instrutores, dividindo-se o trabalho de controle de qualidade entre todo o pessoal de produção;

. a remuneração passa a se basear em resultados, com maior enfoque nas medidas de desempenho;

. ocorre mudança de valores, que passam a inspirar a produção, ao invés de apenas proteger a organização;

. ocorre achatamento das estruturas organizacionais;

. de controladores do resultado os executivos passam a exercer a liderança;

. a preparação dos empregados para o serviço muda, abandonando-se a visão de treinamento operacional em prol de uma dimensão mais abrangente de educação.

Além das decorrências de maior impacto, que envolvem redefinição do próprio negócio e mudanças nas relações com a sociedade e com o ambiente, a mudança organizacional pode vir a gerar diferentes impactos nas relações de trabalho, em especial no nível das instâncias microssociais definidas por Melo (1991) e por Siqueira (1991), como a seguir se explicita. 
(1) Organização do trabalho. Surgem novas maneiras de dividir e sistematizar as tarefas e o tempo entre grupos de trabalhadores; tornam-se maiores as exigências de especialização e de qualificação. Alteram-se as seqüências, os ritmos e as cadências do trabalho; padroniza-se o processo de trabalho. Abrem-se maiores possibilidades de participação do trabalhador na programação.

(2) Gestão da força de trabalho. Mudam as formas de coordenação e controle do desempenho dos trabalhadores, incluindo-se novas técnicas de captação e provisão, controle, compensação, de manutenção e desenvolvimento dos recursos humanos.

(3) Condições de trabalho. Evidencia-se a necessidade de enfatizar a promoção e a manutenção da qualidade de vida no trabalho, não apenas no que concerne às condições ambientais, à segurança no trabalho e à saúde do trabalhador, mas também à subjetividade do empregado, refletindo a representação de seu modo específico de trabalhar/desgastar-se, incluindo a saúde mental e o stress.

(4) Formas de regulação de conflito. Adotam-se diferentes processos de controle ideológico, a fim de favorecer a identificação e mesmo o conformismo dos atores com os objetivos organizacionais. Enfatizam-se a autonomia e a participação como meios de regulação de conflito.

Reportando-se a esse quadro teórico e à base conceitual, utilizada por grande parte das organizações brasileiras nos seus processos de mudança, o presente artigo visa a identificar e analisar os impactos da utilização de novas tecnologias de produção e de gestão sobre as relações de trabalho numa organização produtora de jornais, após a reestruturação da sua forma de produção, cujas principais estratégias foram a demissão de parte de seu quadro, a introdução de maquinário eletrônico de última geração, assim como a definição de novas áreas de atuação.

\section{Metodologia}

\section{A Amostra}

A amostra se compôs de 11 empregados do setor de sistemas de produção e préimpressão do jornal, escolhidos aleatoriamente e com base na sua disponibilidade, nos horários em que foi possível o acesso às diversas áreas de trabalho. A amostra representou $47,8 \%$ do pessoal lotado no setor.

Entrevistaram-se os ocupantes dos cargos de gerente de sistemas de produção, chefe de suporte técnico, chefe de serviço de sistemas, analistas, programadores, 
operadores e encarregados de suporte operacional. A amostra se compôs de empregados de ambos os sexos, com faixa etária entre 22 e 35 anos e com tempo de serviço na organização variando entre 1 e 16 anos.

\section{Instrumentos de Coleta de Dados e de Análise dos Dados}

Utilizaram-se entrevistas semi-estruturadas e observação direta, como fontes de dados. Priorizou-se a coleta de informações relativas à percepção dos entrevistados quanto à situação de trabalho no momento atual, comparativamente ao período imediatamente anterior à implantação da nova tecnologia de produção.

As entrevistas foram encaminhadas segundo roteiro preestabelecido, de maneira que possibilitasse a observação e a análise de aspectos relativos à organização do processo de trabalho, à gestão da força de trabalho, às condições de trabalho e saúde do trabalhador, bem como às formas de regulação de conflitos, instâncias previamente definidas como norteadoras da investigação.

Para tornar mais precisa a análise dos depoimentos, elaborou-se uma matriz de respostas, com as principais falas dos entrevistados. De cada aspecto levantado foram destacadas as falas que agregaram maior conteúdo e significância para a análise pretendida. Nesses casos, preservou-se, na íntegra, o discurso pronunciado.

\section{Caracterização da Organização e da Situação Estudada: Inovação tecnológica, Reestruturação Produtiva e Relaçóes de TrabalHo}

Atuando de maneira diversificada na disseminação da informação - televisão, rádio e jornal - a organização é composta por várias empresas subordinadas. Neste estudo, analisou-se o setor de gerência de sistemas de produção, ligado à área responsável pela produção de jornais, de cujo mercado a organização é líder em um dos Estados da Região Sudeste do Brasil.

No presente, o parque de produção e de impressão de jornais vem sendo constantemente instado à modernização, devido à concorrência e também ao fato de que o jornal diário é um tipo de produto extremamente perecível, cujo atraso na distribuição pode significar perda completa da produção do dia. Por vários anos os sistemas informatizados de grande porte se apresentaram como a maneira mais eficiente de promover o fornecimento de notícias inéditas ou mais recentes possível. Tal tecnologia, porém, tornou-se obsoleta diante das redes de 
microcomputadores, que se revelaram mais dinâmicas e de maior viabilidade econômica, por se tratar de sistema mais flexível, facilmente configurável aos diferentes portes e necessidades de cada organização produtora de jornais.

Em vista da necessidade de adequação à nova tecnologia disponível e às exigências de agilidade de resposta ao mercado, vêm ocorrendo mudanças no modo de produção de jornais, com reflexos diretos na gestão da força de trabalho empregada pelo setor.

Na organização em estudo, a busca de maior competitividade no setor de mídia impressa, por meio da mudança no seu equipamento de produção, ensejou a sua associação a uma empresa norte-americana da área de produção de sistemas informatizados para produção de jornais. Tal união permitiu que a organização modernizasse a sua produção, tornando-a mais competitiva e imprimindo maior qualidade ao seu produto. A parceria se consolidou a ponto de se descortinar novo negócio para a organização: a prestação de serviços de desenvolvimento, instalação e manutenção de sistemas de informática para jornais do Brasil e da América Latina.

\section{A Organização do Processo de Trabalho}

O grupo pesquisado é jovem, com idade média de 26 anos, apenas 2 integrantes acima de 30. Coincidentemente, esses últimos são também os de maior tempo de trabalho na organização. A média de atuação na organização atinge 3 anos. A amostra é composta predominantemente de indivíduos do sexo masculino (82\%).

O grau de instrução varia de segundo grau completo a terceiro grau completo, sendo predominante esse último. A organização vem orientando aqueles que não completaram o curso universitário a obterem o diploma. Tal diretriz - para alguns uma forma de pressão - é justificada pelo fato de que, após a regulamentação da profissão de programador e analista, haverá obrigatoriedade de curso superior para provimento dos cargos.

O predomínio de indivíduos jovens na área pesquisada parece ter relação com a tecnologia utilizada, que exige mão-de-obra formada na área de informática, composta de profissões para as quais o sistema de ensino passou a atentar somente a partir do final da década de oitenta, quando o mercado de trabalho intensificou a demanda por profissionais graduados. Adicionalmente, a resistência à adoção e ao aprendizado desse tipo de tecnologia pelos indivíduos de maior faixa etária pode, em parte, explicar a situação descrita.

Entre os entrevistados, foi possível notar-se certo orgulho pela situação de se trabalhar com tecnologia de ponta, em atividades definidas por um dos entrevista- 
dos como "modernas, estimulantes, desafiadoras e pouco rotineiras". Esse parece ser fator de motivação e de envolvimento no trabalho.

Na observação das funções e das atribuições de cada entrevistado, verificou-se ter havido promoção após a implementação da nova tecnologia de produção, paralelamente ao enriquecimento de tarefas. Não se identificaram práticas que configurassem polivalência dos empregados; mesmo com o trabalho tendo-se tornado mais especializado, a inserção dos empregados não ocorre em outras etapas do processo de produção, senão naquelas específicas de cada cargo. Embora os entrevistados tenham mencionado a polivalência como nova característica do seu trabalho, observou-se que o conceito que eles têm do termo se limita à capacidade de substituir um colega da mesma equipe, fato corriqueiro na organização, principalmente devido aos freqüentes deslocamentos de pessoal para prestação de serviço em outras organizações.

A própria natureza do trabalho realizado no setor permite relativo grau de autonomia e criatividade por parte dos executores. O problema, o resultado esperado e algumas poucas formas de padronização, como o formato final das páginas do jornal e o corpo das letras, são definidos pela organização, ficando a critério do executor a escolha da melhor maneira de realizar o trabalho.

Indagados sobre a possibilidade de desenvolvimento de novas formas de execução do trabalho, os entrevistados foram unânimes em apontar que, quando cabíveis, todas as novas idéias surgidas da equipe, como as referentes à produção, à divisão do trabalho e às escalas de serviço, são absorvidas no processo de trabalho diário. Em alguns casos a difusão foi horizontal, para os colegas da equipe; na maioria dos casos, houve comunicação à chefia imediata, seguida da sua aprovação e da implantação dos novos procedimentos nos níveis hierárquicos pertinentes.

Nenhum dos entrevistados afirmou ter apresentado sugestão para modificar algum ponto do processo de trabalho, que não tenha sido difundida, no mínimo, para seus colegas de equipe. Num processo que parece habitual na organização, uma sugestão de caráter operacional ou administrativo, que mereça ser implementada, chega primeiramente à chefia imediata do seu idealizador e, após analisada, daí se difunde naturalmente para os outros membros da organização que tenham interesse ou que ocupem um cargo envolvido no processo suscetível de alteração.

Com a introdução da nova tecnologia de produção, verificou-se aumento no grau de complexidade das tarefas, evidenciando-se a necessidade de maior qualificação dos trabalhadores. Um exemplo dessa ocorrência pôde ser verificado no trabalho do ocupante do cargo de codificador de matérias, caracterizado anterior- 
mente por atividades extremamente simples e repetitivas, que requeriam muito pouco raciocínio, criatividade ou formação escolar. Após a mudança tecnológica, o cargo foi extinto; para se manter na organização, o seu ocupante necessitou passar por longo processo de aprendizado, a fim de assumir cargo na área de suporte operacional, assumindo a função intermediária de operador de sistemas, com grau de complexidade e exigência de raciocínio superiores.

Outra decorrência da mudança tecnológica foi uma nova orientação rumo à criação de equipes de trabalho, cuja atividade é pautada pela participação e pela união de esforços. A figura do chefe passou a ter caráter menos impositivo, evidenciando-se a necessidade de atributos de liderança e de coordenação de esforços.

Nas respostas dos entrevistados a respeito da divisão do trabalho, ficou ressaltado um sentimento de autonomia quanto à execução do trabalho, contanto que se respeitem as normas e os padrões de qualidade definidos para o trabalho e para os produtos. A maioria dos entrevistados relatou que as descobertas de novas formas de atingir os objetivos de produção geralmente são acatadas e difundidas. Essa parece uma diretriz se não da organização como um todo, pelo menos da área pesquisada. Parece haver um clima de abertura no qual, segundo um dos entrevistados, "[...] não há donos de idéias. Pelo contrário, elas passam a pertencer a todo o grupo, incluídas as chefias, como mais um componente a auxiliar nos esforços de produção e de desenvolvimento, promovendo o engajamento do grupo".

Pôde-se perceber que a supervisão e o controle do processo de trabalho ocorrem por meio da aferição dos resultados: se o trabalho apresenta alguma falha, logo se percebe pelos erros na impressão do produto ou por alguma pane no sistema de produção. Na área de desenvolvimento de programas, é habitual a prática do préteste dos sistemas, caracterizado pelo que os empregados chamam de autoconferência, processo a partir do qual o próprio equipamento auxilia na identificação dos erros, sugerindo procedimentos e alternativas para modificação e ajuste das etapas.

\section{A Gestão do Processo de Trabalho}

A maioria dos entrevistados recebeu algum tipo de treinamento específico para a função que ocupavam anteriormente ou para aquela que viriam a ocupar após as mudanças ocorridas com a informatização da organização.

Os treinamentos são constantes e ocorrem no próprio local de trabalho, ministrados por colegas ou chefes. Poucos foram os entrevistados que relataram ter participado de alguma atividade de treinamento fora da organização e, mesmo 
assim, tais atividades se restringiram a cursos de línguas, cursos de programação em nova linguagem ou aprendizado de novos sistemas operacionais. Dentre todas, a área de suporte técnico é a que vem recebendo maior investimento em treinamento e qualificação, por ser área vital que deve, segundo um dos chefes entrevistados, "congregar todo o conhecimento e repassá-lo ao restante da organização”.

Dada a natureza interna dos treinamentos, observou-se que os próprios empregados não percebem como treinamento e qualificação tais atividades implementadas pela organização. Os programadores, por exemplo, relataram que nunca passaram por qualquer tipo de treinamento enquanto, entre os operadores, apenas um afirmou ter recebido treinamento, cujos conhecimentos proporcionados nunca foram, segundo ele, utilizados no serviço.

Ao contrário dos programadores, que já detinham qualificação anterior, os operadores passaram obrigatoriamente por algum tipo de qualificação, ao serem promovidos no período de mudança do sistema de operação. Esse treinamento inicial não se mostrou suficiente, já que a mudança é dinâmica, exigindo treinamentos constantes nas linguagens que vêm sendo incorporadas ao sistema atual.

Dessas observações derivam duas constatações: primeiramente, por medida econômica, apenas um membro da organização habitualmente recebe treinamento externo e é incumbido de repassar os conhecimentos para os demais colegas de trabalho. Em segundo lugar, em tais treinamentos se priorizam aspectos tecnológicos e operacionais específicos da atividade-fim da organização. Não se colheu relato algum de treinamentos de natureza gerencial, administrativa ou na área comportamental, matérias habitualmente incluídas nos planos de desenvolvimento de pessoal das organizações modernas, principalmente quando se pretende implementar mudanças do porte daquelas que ocorreram na organização.

Mesmo tendo considerado a remuneração na média de mercado, a maioria dos entrevistados julga receber salários baixos, proporcionalmente ao ritmo e ao volume de serviço que a organização lhes vem impondo. No momento da pesquisa, os salários dos entrevistados se encontravam num nível inferior à média de mercado, tendo o pessoal da equipe de suporte técnico informado que, no caso dos seus cargos, os salários geralmente se encontram abaixo da média de mercado. Os entrevistados utilizam o termo sazonalidade para identificar períodos em que os salários ficam num nível inferior, em decorrência das diferentes datas-base das categorias.

A despeito da importância que assumem no contexto da mudança organizacional, orientada para a produtividade e a competitividade, as recompensas têm-se limitado a eventuais aumentos salariais. Dado seu valor relativamente elevado em 
comparação com os salários, são também consideradas recompensas as diárias pagas ao grupo de suporte técnico, que habitualmente viaja para prestação de serviços a outras organizações. Em termos de promoções, os entrevistados apontaram unicamente os aumentos salariais ocorridos nos últimos três anos (apenas um deles não foi promovido nesse período) e algumas promoções a cargos mais elevados na escala hierárquica ocorridas com a mudança tecnológica e administrativa. Em grande parte, a atual equipe é composta pelos sobreviventes do processo de inovação tecnológica. Tais remanescentes passaram a receber maiores salários nos novos postos de trabalho.

Como decorrência da reestruturação, houve corte de pessoal, optando-se por manter o maior número possível de empregados da própria área. Embora tenha havido novas contratações, elas ocorreram em menor número do que as demissões. Segundo os entrevistados, só não permaneceram aqueles que não demonstraram condições mínimas de aprendizado e aqueles que recebiam salários mais elevados em cargos que foram extintos. Segundo relato do gerente do setor, nesses casos havia impedimento legal para a manutenção dos empregados em cargos que pudessem configurar uma situação de rebaixamento salarial.

A despeito de os salários não representarem diferencial significativo em relação ao mercado de trabalho dos profissionais entrevistados, apenas um deles relatou sentir que não recebe da organização a recompensa justa pelo seu trabalho e pela sua dedicação. Nota-se no grupo a orientação para outros valores como calor humano, apoio e trabalho em equipe, assim como forte sentimento prazeroso, de orgulho mesmo, por realizar um trabalho considerado "[...] de ponta, que não se aprende no banco de escola, mas no dia-a-dia de um jornal, no qual é possível a constante incorporação de novos conhecimentos para responder aos freqüentes desafios".

Da mesma forma, a maioria dos entrevistados percebe seu trabalho atual como atividade "em que se dá muito mas sempre se recebe algo em troca", o que evidencia o envolvimento do grupo pesquisado, em clima de conformidade com os valores e padrões correntes na organização.

\section{Condiçőes de Trabalho e Saúde do Trabalhador}

O trabalho realizado pelos entrevistados não apresenta elementos indicativos de condições insalubres ou perigosas. Quanto ao risco de doenças ocupacionais, verificou-se a ocorrência de problemas oftalmológicos entre os digitadores e os programadores, com necessidade de utilização de óculos. Embora se possa prever a existência de casos de tendossinovite entre trabalhadores informáticos, principalmente entre programadores e digitadores, dada a natureza repetitiva de algumas 
das suas atividades, não se verificaram casos da doença na área pesquisada. Como a evolução das lesões por esforço repetitivo se processa lentamente, é provável que futuramente venham a surgir casos entre os trabalhadores da área, principalmente ao se considerar que grande parte deles vem mantendo ritmo intenso de trabalho e jornadas que ultrapassam em muito as oito horas diárias.

Por sinal, a intensificação do trabalho é assunto recorrente no relato dos entrevistados. Notadamente entre os profissionais que ocupam cargos nos níveis hierárquicos mais elevados ou naqueles cargos que exigem tratamento direto com clientes na área de suporte operacional e na manutenção de sistemas, colheram-se relatos de cansaço físico e mental, de trabalho intensificado após as mudanças na organização e de uma média de realização de trabalho extraordinário elevada. Os profissionais acreditam que alguns problemas dermatológicos e o cansaço mental exacerbado que os acometem regularmente sejam indícios de stress ocupacional ${ }^{(2)}$.

A intensificação do trabalho é percebida de maneiras diferentes pelos entrevistados. Para a equipe de produção, a jornada de trabalho é classificada como razoável ou tranqüila. Para esse grupo, a informatização contribuiu para reduzir o cansaço. Esporadicamente ocorrem períodos de trabalho mais intenso, porém a média de horas extraordinárias é baixa.

Já a equipe de programação considera a jornada intensa, tendo sentido mais cansaço nos últimos seis meses, mesmo perfazendo um total de horas extraordinárias inferior a dez horas por mês. O chefe da equipe costuma perfazer mais de trinta horas extraordinárias por mês.

Os profissionais da equipe de suporte operacional consideram intensa a sua jornada de trabalho, principalmente quando viajam em atendimento a clientes. Nesses períodos, eles costumam cumprir jornadas diárias de treze horas. Da mesma forma, aqueles que acumulam as tarefas dos que estão em viagem ultrapassam as trinta horas extraordinárias mensais, trabalhando nos domingos e nos feriados.

A equipe de suporte técnico considera intensa a sua jornada de trabalho e relata sentir cansaço freqüente nos últimos meses. É o grupo com maior número de horas extraordinárias, todos com mais de trinta horas mensais e chegando-se, num dos casos, a oitenta horas.

A intensificação do trabalho ficou evidenciada sobretudo entre os profissionais que acumulam funções de gerência de setores e de gestão de pessoal. Os trabalhadores que executavam tarefas mais simples antes da informatização relataram que o trabalho se tornou menos intenso. Essa percepção parece não se dever à redução efetiva do volume de trabalho, mas ao aumento do interesse desses em- 
pregados pelas novas tarefas, com seus desafios e possibilidades criativas. Possivelmente, o modelo de gestão tendentemente democrático atualmente adotado venha contribuindo para a intensificação do trabalho, no sentido de que a gestão mais interativa e liberal exige maiores esforços e maior mobilização emocional dos gestores, na tentativa de satisfação dos empregados.

Se, por um lado, tal método de gestão pode encerrar alguns aspectos positivos para os indivíduos - valorização, reconhecimento, sentido à atividade profissional, dentre outros - igualmente pode ser fonte de grande tensão: quando a organização abandona ou modifica essa forma de gestão, os indivíduos tornam-se vulneráveis, principalmente aqueles que investiram mais na relação com a empresa (Chanlat, 1996).

Em termos das condições físicas de trabalho, a utilização constante e maciça de equipamento de informática exige instalações especiais e determina alguns procedimentos que, segundo os entrevistados, contribuem para tornar desagradável ou desconfortável o trabalho:

. baixa temperatura ambiental, para evitar o superaquecimento das máquinas;

. ausência de janelas que possibilitem ventilação e iluminação naturais;

. utilização constante de condicionadores de ar, o que impede renovação da atmosfera;

. condições ergonômicas inapropriadas do mobiliário sobre o qual são instalados os equipamentos.

\section{Formas de Regulação de Conflitos}

Indagados sobre a participação no processo de tomada de decisão, a maioria dos entrevistados apontou serem as decisões discutidas entre colegas e superiores, embora sejam tomadas independentemente da existência de algum tipo de consenso por parte do grupo. Três entrevistados revelaram ter envolvimento parcial na tomada de decisões, referindo-se a situações em que se evidenciam as relações de poder: eles acabam sentindo-se como instrumentos de legitimação das decisões superiores ou, como define um deles, "elementos que juramentam o que os chefes decidem, para dar uma impressão de trabalho conjunto, de um senso de coesão da equipe". Outro entrevistado relatou que é apenas informado pelo seu superior a respeito das decisões tomadas na organização. Contrariamente a esses depoimentos, um dos chefes entrevistados apontou as decisões como "amplamente discutidas com os subordinados", observação contra-argumentada por esses subordinados, que classificaram tal prática como muito rara e "artifici- 
al". De maneira geral, as decisões de maior amplitude, impacto e risco - as "estratégicas", segundo um dos entrevistados - são tomadas pela cúpula da organização, ficando a cargo dos entrevistados as decisões operacionais relativas ao nível e ao setor em que trabalham.

Pelo exposto, pode-se verificar que, a despeito de as metas, procedimentos e objetivos serem elementos previamente definidos pela organização, ocorre participação dos empregados na definição das formas de implementar as metas determinadas. Pelo menos nesse nível, é forte o envolvimento das equipes. De todo o modo, a participação nas decisões é tanto maior quanto mais próximos da cúpula se localizam os empregados. Nos níveis hierárquicos mais distanciados da alta gerência, registraram-se reclamações quanto à restrição de autonomia na escolha da forma de consecução do trabalho.

Embora se esteja referindo a participação, convém destacar que "a participação, em sua concepção mais abrangente, implica um processo em que cada indivíduo detém igual poder para determinar o produto da decisão" (Fleury e Fischer, 1987). Nesse sentido, deve-se ter em mente que a estrutura de poder é aspecto fundamental num modo de gestão. Em grande medida, é o que o determina (Fleury e Fischer, 1987; Melo, 1991; Siqueira, 1991). No caso da organização estudada, não houve mudança significativa na distribuição de poder, uma vez que a autonomia se manteve restrita apenas a aspectos cotidianos e operacionais do trabalho.

Quanto ao ambiente social em que transcorrem as relações de trabalho, foi possível identificar a existência de canais de expressão que parecem favorecer a regulação de conflitos entre os empregados. A abertura no tratamento das opiniões, reclamações e sugestões parece configurar um estilo mais democrático de gestão da força de trabalho. Segundo um dos entrevistados, contudo, estabeleceuse forte clima de insegurança, a partir da reestruturação e das demissões ocorridas. A estratégia da organização para minimizar os efeitos dessa insegurança foi a introdução de reuniões periódicas entre as equipes e os seus superiores imediatos, até como forma de reforçar o sentimento de equipe e o vínculo entre os diversos níveis hierárquicos.

Percebe-se que a organização institucionalizou a participação como forma de manter o equilíbrio entre os diversos interesses envolvidos. Nesse momento, pode entrar em ação um forte elemento simbólico, capaz de atuar como agente integrador e estimulador da produtividade: é o senso de pertencer. Assim, como componentes da estratégia de gestão, as reuniões passam a representar tanto um elemento de comunicação e consenso, quanto um mecanismo de regulação de conflitos, o que, em última instância, não deixa de ser uma forma de controle sobre a força de trabalho ${ }^{(3)}$. 


\section{Consideraçóes Finais}

Em resposta à necessidade de imprimir maior agilidade, qualidade e rapidez à produção de jornais, a organização estudada apelou para a renovação tecnológica do processo produtivo na parceria com uma empresa americana, o que possibilitou a instalação de microcomputadores em rede, em substituição a computadores de grande porte. Além da mudança tecnológica, tal parceria possibilitou a diversificação das atividades da organização, que passou também a prestar serviços para organizações similares no país e na América Latina. A despeito da abertura de nova frente de atuação no mercado - a venda de sistemas informatizados para jornais - $\mathrm{o}$ antigo negócio continua a ser a atividade principal.

Como conseqüência direta dos processos de reestruturação tecnológica e de entrada em novo ramo de operações, surgiu o imperativo de mudança abrangente e profunda, que alcançou a instância da gestão da força de trabalho, e requereu o estabelecimento de relações de trabalho mais flexíveis e liberais. Em termos de organização do processo de trabalho, cargos e funções foram eliminados ou substituídos, tendo sido completamente remodelado o processo de trabalho. Os depoimentos indicam que as mudanças transcorreram em ritmo mais lento, procurando-se impactar a organização de modo mais suave, garantindo avanços tímidos com menores riscos.

De todo o modo, abaixo podem ser observadas algumas práticas; elas vão se configurando como novo padrão das relações de trabalho no interior da organização estudada.

(1) Tendência à transformação dos departamentos em equipes de trabalho. As equipes, todavia, não apresentam caráter multidimensional, conforme salientam Hammer e Champ (1994). Ocorreu forte especialização nas funções de cada equipe.

(2) Embora os papéis continuem a ser desenhados pela organização, há um esforço de se promover a interação do empregado, através da abertura para sugestões, reivindicações e críticas, quanto ao processo de trabalho.

(3) A supervisão se apresenta mais flexível, dispondo de canais de informação mais efetivos, promovendo certa autonomia e autocontrole da qualidade do trabalho. Tais atitudes podem explicar, em parte, o interesse, o senso de responsabilidade e a motivação observados nos empregados. Também podem ser a explicação para o relato de que não existem maiores conflitos entre os empregados nas equipes e nas relações hierárquicas. Nesse aspecto, a adoção das reuniões como espaço de discussão e de reivindicações contri- 
buiu para a exposição dos problemas, para a busca de suas soluções e para o acerto de contas entre os membros das equipes e as chefias.

(4) A despeito da insegurança inicialmente gerada pelas demissões, a redução dos níveis hierárquicos propiciou aos empregados maior fluidez no acesso a informações e um conhecimento aprofundado da organização como um todo, bem como maior envolvimento com a sua administração.

(5) A atitude mais democrática assumida pelas chefias, direcionada mais à liderança e à coordenação de esforços do que propriamente à imposição de ordens, parece vir contribuindo para a evolução das relações de trabalho e para o aumento da produtividade.

Ao lado dos aspectos positivos observados na reestruturação da organização, alguns traços apontam para a dificuldade de abandono de tradicionais práticas de gestão e de relações de trabalho. Ilustram tal situação a manutenção de formas de controle como cartão de ponto, a rigidez no modelo de remuneração, a noção de desenvolvimento de pessoal baseado exclusivamente em treinamentos direcionados aos requisitos tecnológicos do trabalho, pensando-se no empregado como executor que deve ser mais e mais especializado nas tarefas que lhe cabem e não na educação e no crescimento do indivíduo.

Há que se mencionar uma percepção que parece comum aos membros da organização em relação ao trabalho e à posição do trabalhador brasileiro, em face dos novos desafios impostos pela tecnologia. Como expressão de forte assimilação dos novos valores organizacionais ou mesmo de ponto de vista peculiar aos profissionais da área tecnológica, a adoção de novas tecnologias de produção é vista apenas pelo lado positivo. Para eles, a atualização tecnológica é ocorrência natural, imprescindível e inadiável, cabendo ao trabalhador esforçar-se na adaptação aos novos tempos e às novas imposições do mercado.

Nesse particular, fica a impressão de que, para o grupo pesquisado, importa menos o lado perverso da inovação tecnológica, que desconsidera a questão estrutural do trabalho no país, as limitações culturais do trabalhador brasileiro e o seu choque diante dos novos paradigmas de produção, que invariavelmente padronizam atitudes, ceifam postos de trabalho e excluem maiores possibilidades de criação.

Por fim, cabe lembrar que os fenômenos e situações aqui retratadas refletem o ponto de vista dos sobreviventes do processo de inovação tecnológica, indivíduos que se mostraram capazes de passar por um período de adaptação relativamente longo e podem ter vindo a perceber como pessoais alguns valores estrategicamente incorporados à cultura organizacional, após a reestruturação, os quais têm o 
efeito de potenciar os mecanismos de dominação e de regulação de conflitos da organização.

\section{Notas}

${ }^{1}$ Uma breve compilação das diversas correntes teórico-práticas sobre mudança organizacional pode ser encontrada no artigo Mudança Organizacional: Introdução ao Tema, de Wood Jr. (1995).

${ }^{2}$ A organização do trabalho tem sido apontada como um importante fator causador de problemas de saúde física e mental. Ver, por exemplo, os artigos de Dejours (1987), Chanlat (1992, 1996), Dejours, Adboucheli e Jayet (1994), Codo e Sampaio (1995).

${ }^{3}$ Diversos estudos têm comprovado tal afirmação. Um dos mais conhecidos se encontra em Cultura e Poder nas Organizações, de Fleury e Fischer (1992), obra que traz diversos artigos sobre o tema.

\section{RefERÊNCIAS Bibliográficas}

CHANLAT, J. F. (Coord.).

O indivíduo na organização : dimensões esquecidas. São Paulo : Atlas, 1992.

Modos de gestão, saúde e segurança do trabalho. In: DAVEL, E.; VASCONCELOS, J. 'Recursos' humanos e subjetividade. Petrópolis : Vozes, 1996.

CODO, W.;

SAMPAIO, J. J. C. (Orgs.).

Sofrimento psíquico nas organizações : saúde mental e trabalho. Petrópolis : Vozes, 1995.

DEJOURS, C.

A loucura do trabalho. São Paulo : Oboré Editorial, 1987.
DEJOURS, C.;

ABDOUCHELI, E.;

JAYET, C.

Psicodinâmica do trabalho : contribuições da escola dejouriana à análise da relação prazer, sofrimento e trabalho. São Paulo : Atlas, 1994.

FLEURY, M. T. L.;

FISCHER, R. M. (Orgs.).

Cultura e poder nas organizações. São Paulo : Atlas, 1992.

Processo e relações do trabalho no Brasil. São Paulo : Atlas, 1987. 
GONÇALVES, J. E. L.

Reengenharia : um guia de referência para o executivo. Revista de Administração de Empresas, v. 34, n. 4, p. 26, jul./ago. 1994.

HAMMER, M.;

CHAMPY, J.

Reengenharia - revolucionando a empresa. 14. ed. Rio de Janeiro : Campus, 1994.

LEITE, M. P.

O futuro do trabalho : novas tecnologias e subjetividade operária. São Paulo : Scritta, 1994.

MELO, M. C. O. L.

Estratégias do trabalhador informático nas relações de tra- balho. Belo Horizonte, 1991. Tese (Titular) - Universidade Federal de Minas Gerais.

SIQUEIRA, M. M.

Relações de trabalho em hospital público e privado de Belo Horizonte: análise de grupos de residentes, pessoal de limpeza e auxiliares de enfermagem. Belo Horizonte, 1991. Tese (Livre Docência) - Centro de Pós-Graduação e Pesquisa em Administração, Universidade Federal de Minas Gerais.

WOOD JR., T.

Mudança organizacional : aprofundando temas atuais em administração de empresas. São Paulo : Atlas, 1995. 